DOI: 10.20472/IAC.2019.045.021

QURA-TUL-AAIN KHAIR

National College of Business Administration and Economics, Pakistan

\title{
IMPACT OF FEAR ON NEGATIVE EVALUATION ON EMPLOYEE PROMOTIONAL AND PROHIBITIONAL VOICE BEHAVIOR
}

\begin{abstract}
:
Personal and social relationships fulfill individuals' basic needs of belongingness, control, self-esteem and meaningful existence. These needs further motivate individuals to positively evaluated by others in workplace. Based on Conservation of resource theory (COR) this research study has tried to investigate the impact of fear of negative evaluation on employee promotional and prohibitional voice behavior. This model has explained that the fear of negative evaluation could lead employees to maximize the promotional voice and minimize the use of prohibitional voice in order to gain control on one's environment and to prove oneself. Use of promotional voice is helpful to acquire more resources in workplace whereas the use of prohibitional voice facilitates to conserve the available resources.

Data was collected from education sector of Pakistan, comprising faculty and non-faculty members working at different hierarchical levels in public and private school, colleges and universities. Results have confirmed hypotheses and found a significantly positive relationship between fear of negative evaluation and promotional voice and negative relationship between fear of negative evaluation and prohibitional voice. This paper has used SPSS and AMOS tools for data analysis. Future recommendations are to include other types of voice behavior and also expand the sample population to other sectors.
\end{abstract}

\section{Keywords:}

Fear of negative evaluation (FNgE), Employee Promotional Voice (PMV), Employee Prohibitional Voice (PBV) and Conservation of Resource Theory (COR). 